\title{
VIDEO ANALYSIS AND 3D DETECTION SIMULATION OF JUMP SHOT PRECISION FOR BASKETBALL PLAYERS
}

\author{
ANÁLISE DE VIIDEO E SIMULAÇÃO DE DETECÇÃO 3D DA PRECISÃO DO ARREMESSO DE JOGADORES \\ DEBASQUETE
}

\begin{abstract}
ANÁLISIS DE VIDEO Y SIMULACIÓN TRIDIMENSIONAL DE LA PRECISIÓN DE LANZAMIENTODE LOS JUGADORESDE BALONCESTO
\end{abstract}

\begin{abstract}
Yi Zheng1 (ID
(Public Health Education)

1. Physical Education Institute of XuChang University, XuChang, Henan, 461000, China.
\end{abstract}

\section{Correspondence:}

XuChang, Henan, 461000, China. gc303nepe705@126.com

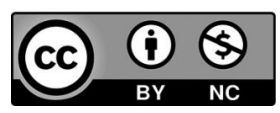

\begin{abstract}
With the rapid development and application of computer technology, the application of computer science knowledge in basketball is also more and more extensive. Based on genetic algorithm and the background subtraction method, video analysis and 3D detection simulation model of shot jump action precision were constructed in this study. According to the genetic algorithm search method, jump shot precision was analyzed, and the problems encountered in the actual shooting process of basketball players were studied and solved. The results show that this study is necessary and feasible.
\end{abstract}

Keywords: Algorithm; Basketball; Subtraction Technique

\section{RESUMO}

Com o rápido desenvolvimento e aplicação da tecnologia da computação, a aplicação do conhecimento da ciência da computação no basquete também vem crescendo cada vez mais. Com base no algoritmo genético e no método da subtração de fundo, construiu-se um modelo de análise de vídeo e simulação de detecção 3D para a precisão de arremesso. De acordo com o método de busca do algoritmo genético, analisou-se a precisão do arremesso, e os problemas encontrados no processo de arremesso dos jogadores de basquete foram estudados e resolvidos. Os resultados mostram que este estudo énecessário e viável.

Descritores: Algoritmo; Basquete; Técnica de Subtração

\section{RESUMEN}

Con el rápido desarrollo y aplicación de la tecnología de la computación, la aplicación del conocimiento de la ciencia de la computación en el baloncesto también viene creciendo cada vez más. Basándose en el algoritmo genético y en el método de la sustracción de fondo, se construyó un modelo de análisis de video y simulación de detección 3D para la precisión de lanzamiento. De acuerdo con el método de búsqueda del algoritmo genético, se analizó la precisión del lanzamiento, y los problemas encontrados en el proceso de lanzamiento de los jugadores de baloncesto fueron estudiados y resueltos. Los resultados muestran que este estudio es necesario y viable.

Descriptores: Algoritmo; Baloncesto; Técnica de Sustracción.

\section{INTRODUCTION}

Basketball has been widely loved by people. With the continuous development of basketball, the detection technology needs higher requirements for shooting techniques. However, there are many disadvantages in the algorithm of the throwing test, such as difficult installation, trouble making and low accuracy. ${ }^{1}$ So the background difference method is used in this study. Background difference method not only has the characteristics of real-time and high accuracy, but also has good robustness to the uncertain velocity of moving objects and the motion detection of elastic objects. ${ }^{2}$ The specific step is to detect the object by collecting each frame image in the image sequence and comparing it with the background model, which is a way to detect the object. ${ }^{3}$

At present, with the rapid development of computer and sports technology, the 3D detection technology of motion model is more and more widely used in the body positioning system and sports. Shooting is the only way to score in basketball games, so it is necessary to carry out 3D monitoring for basketball players. The existing monitoring model cannot record the throwing status of basketball players in detail. So the research supports a two-dimensional data of the human joint motion curve when the human body shoots in a single video sequence. ${ }^{4}$ Then, the model of 3D data is created on the basis of two-dimensional data. At present, the accuracy of shooting action of basketball players has attracted the attention of the majority of experts. The accuracy test of the throwing is carried out through professional testing equipment and professional measurement personnel.

\section{STATE OF THE ART}

In this series of researches, it is necessary to detect moving objects. The video analysis of the precision of the throwing and 3D detection simulation originated from developed countries in Europe and America. After years of research by scholars and researchers, the detection technology of moving targets has developed rapidly. In China, the application of this technology is mainly in universities and research institutes, and has not been widely used in daily life. 
Therefore, this research is also a great step forward in the application of target motion detection technology. It is necessary to strengthen the throwing of basketball players.

In this study, multiple cameras are used to record the trajectory of body movement of basketball players in the throwing. Then, the images recorded by the camera are analyzed. The scientific and reasonable method is used to record and analyze the technical indexes of jumpers in the throwing. According to the acquired image and data, the 3D data model is constructed. Through the algorithm designed in the model, the technical movements of basketball players in the throwing are corrected and guided, which makes the basketball player faster and better grasp the technical action and scoring rate of the throwing. In this study, the background difference method is used to analyze the moving images. The background difference method is a method to detect moving objects by comparing the current frame and background reference model in image sequences. Its performance depends on the background modeling technology use.

\section{METHODOLOGY}

\section{Construction of three-dimensional detection simulation model for the throwing}

In this paper, 3D detection simulation is used for the throwing, which needs to be checked in the basketball shooting. So the main operation process is the establishment of basic ideas, basic establishment process and background modeling through the throwing movements. The current jump movements of basketball players need reasonable analysis and guidance, because the old training methods have been unable to meet the growing demand for teaching. Research on video analysis and 3D detection simulation of the accuracy of the throwing for basketball players is studied in this paper. In the process of shooting, the basketball movement state is analyzed and compared. First of all, we need to do the processing of the video data. The acquired image signal is collected, and then the data quantization process is taken as the image acquisition. It is necessary to denoise the image in the video. The method of frequency domain image denoising is adopted in this paper. This method transforms the image from the previous spatial domain into the frequency domain. Then, the coefficients of the transformation are calculated, in which the wavelet transform method for spatial domain of image is used. It is converted by the following formula:

$$
g(x, y)=\frac{1}{N} \sum_{f \in R} f(x, y)
$$

Where, $f(x, y)$ is the image to be processed; $\mathrm{R}$ is the inner core; $\mathrm{N}$ counts as the total pixels in the kernel; the average function is $g(x, y)$. This method is called the domain average method, and it is the most intuitive and easiest denoising method in image processing. This method is widely used in the process of image denoising. In fact, it is that to average the number of pixels in the plate, and calculate the new gray value in the region of pixels. By this method, the pixels of the surrounding environment pixels can be represented without eliminating the pixels. Then we can get the desired noise reduction images. To a certain extent, the blurred image is transformed into a clear image. It not only has the above advantages, but also has the advantages of simple and easy to handle in calculation. In addition, the speed of calculation is also very fast. Then the median filter is processed, and the median filter is further processed after the noise reduction of the image. The median filter is to sort the captured images organically in a certain field, and select a suitable value to represent the value within this range. The images can be sorted by the following formula.

$$
x_{1} \leq x_{2} \leq x_{3} \ldots \leq x_{n}
$$

Where, $x$ is the middle number of all pixels in this field.

$$
x=\operatorname{Med}\left\{x_{1} \leq x_{2} \leq x_{3} \ldots \leq x_{n}\right\}=\left\{\begin{array}{c}
\frac{x_{n+1}}{2} \\
\left(\frac{x_{n}}{2}+\frac{x_{n+1}}{2}\right) / 2
\end{array}\right\}
$$

In the use of median filtering method of processing, the original image becomes clearer. By contrast, it can be found that after the median filtering technology is processed, the pixels of the obtained image can be randomly arranged from the new. The specific process is shown in Figure 1.

When the scene changes with time, it is necessary to update the background model and image in real time. Therefore, the research model

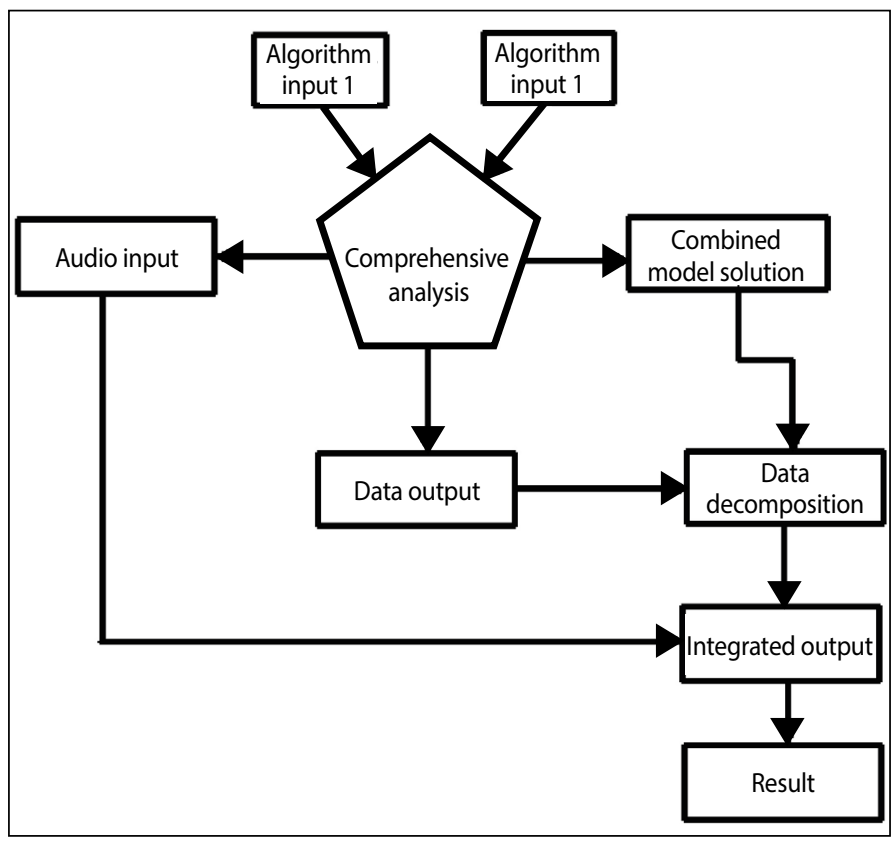

Figure 1. Basketball jump shot flow chart of algorithm.

needs to be improved and optimized on the basis of the original to better serve the subject. So this is the mean method of background modeling method, because the shooting situation of basketball model is relatively simple. Mean value method is a method based on statistical over filtering. The images captured by the high speed camera are processed for a period of time. Then the accumulated value is divided by the captured frequency, and an average value can be obtained. Take this average as the background model. It can be calculated by the following formula.

$$
p\left(x_{t}\right)=\frac{1}{N} \sum_{i=1}^{n} K_{h}\left(x_{1}-x_{t}\right)
$$

Where, Kh represents the kernel function, and $\mathrm{h}$ represents the width of the core function. After the calculation, the feature pixel standard deviation is calculated according to the following formula.

$$
\sigma_{m}=\frac{m}{0.68 \sqrt{2}}
$$


Where, $m$ represents the median value of the absolute difference between the pixels of adjacent two frame images, which is expressed by the following mathematical expression.

$$
m=\text { median }\left(\left|x_{i}-x_{i+1}\right|\right)
$$

The images after noise reduction can be adapted to different scenes. In modeling, it is necessary to estimate the parameter line and enter the research work of the algorithm model. Then, the input data is calculated, and the coefficient indexes of the final algorithm model are obtained. The mechanism of the algorithm modeling model can not only make the complexity of the traditional video far away, but also bring different model construction, and optimize the design of basketball video.

\section{Simulation model of video analysis and 3D detection}

$3 \mathrm{D}$ model is needed for the construction of 3D model of basketball jumper's video, which is usually generated by 3D modeling tools. The 3D model combines points with different motion information. At the same time, the three-dimensional algorithm model of athlete body can be generated by this method according to certain algorithm. Although virtual methods exist in computer or computer files, 3D models are widely used in any place where 3D graphics are used. In fact, their main application is the popularity of $3 \mathrm{D}$ graphics on personal computers. The established 3D model uses pre rendered 3D model images as sprite for real-time computer rendering. The 3D model is invisible and can be rendered on different levels of detail by simple wireframe or by shading with different methods (shaded). However, many 3D models use texture to cover, and the process of arranging textures on a 3D model is called texture mapping. So there are many problems in basketball players'3D throwing model. Because the model is based on genetic algorithm, it is necessary to select the threshold. Because the threshold of a genetic algorithm is very important, the results obtained are shown in Table 1.

The genetic optimization algorithm of basketball throwing is a global optimization search method based on natural selection and modern genetic theory. The main features lie in the swarm search strategy of the algorithm and the exchange of information among individuals in the swarm, and the search efficiency is high. GA only uses evaluation function in the optimization process, and does not require differentiability. It has the advantages of global, parallelism, rapidity, adaptability and robustness, which is widely used. The genetic optimization method based on floating point coding has the optimization result with decimal, which is inconsistent with the actual project. In order to solve the problem, the encoding method and initialization range are coded by binary encoding. It not only has the advantages of encoding, decoding, simple operation, crossover, mutation and other genetic operations easy to implement, but also can achieve very simple optimization results as integer goals. The thickness hi $(i=1,2, \ldots, 5)$ of all structural layers of pavement is used as decision variable when the concrete structure is optimized. For this multi parameter optimization problem, binary concatenated coding is adopted. This also determines the decoding method of the problem.

Table 1. Calculation table of threshold value of genetic algorithm.

\begin{tabular}{c|c|c|c}
\hline $\begin{array}{c}\text { Initial output } \\
\text { data }\end{array}$ & $\begin{array}{c}\text { Expectation value } \\
\text { of threshold }\end{array}$ & $\begin{array}{c}\text { Actual value } \\
\text { of threshold }\end{array}$ & $\begin{array}{c}\text { The final } \\
\text { threshold value }\end{array}$ \\
\hline 20 & 10 & 60 & 40 \\
\hline 30 & 10 & 90 & 50 \\
\hline 40 & 10 & 130 & 70 \\
\hline 50 & 10 & 170 & 120 \\
\hline 60 & 10 & 220 & 180 \\
\hline
\end{tabular}

\section{RESULT ANALYSIS AND DISCUSSION}

Based on the video analysis and 3D detection simulation of throwing's accuracy for basketball players, testing the actual application of the built model is needed. Before testing, it is necessary to build a test platform, so as to test the correctness and performance of the algorithm, and also optimize the actual application of the algorithm model in the actual basketball training. Feasibility testing is carried out under the condition of computer software. Based on the previously designed chapter model, the core diagnostic code is written through the computer language Java. Before testing, we need to build a test platform through some software. According to the actual test requirements, based on the B53E technology, the three tiered framework is built. On this basis, in order to facilitate the stability of the test system, the hardware resources of the computer are made full use, and the entire test system platform is built to a Unix terminal server. In addition, it also uses the database and external application server and the external network server, so as to complete the construction of the test platform. First, the performance of the algorithm is tested. The test method is to input 2000 video files of the throwing in the algorithm model, and then test them with the judgment of basketball professional trainers. The performance chart of the algorithm is shown in Figure 2.

After checking whether the algorithm model can be operated quickly, one of the points that need to be detected is that the evaluation index of the most representative model in the genetic algorithm model is the convergence value of the function. The convergence of the algorithm is tested below. Convergence is very important for genetic algorithms. Too fast convergence will lead to the difficulty of calculating the most effective results, and too slow convergence is likely to lead to the failure of the calculation results. So the convergence value of the algorithm is very important. After calculating the convergence value of the algorithm, the test is helpful to the adjustment of the algorithm step. The test uses the Schaffer function and the Shubert function to test the convergence value as shown in Table 2.

For basketball players, the throwing actions are just a matter of the moment. Therefore, the algorithmic model also needs a test of real time. Because there is no time factor in image research, this study solves the problems in the previous system. It is believed that the research and the application of motion capture technology will greatly promote the use and make up for the lack of basketball detection technology. Only when it can occur in the event of timely analysis and processing, the processing time determines the real-time model of the algorithm. So the following tests are needed, and the test results are shown in Table 3.

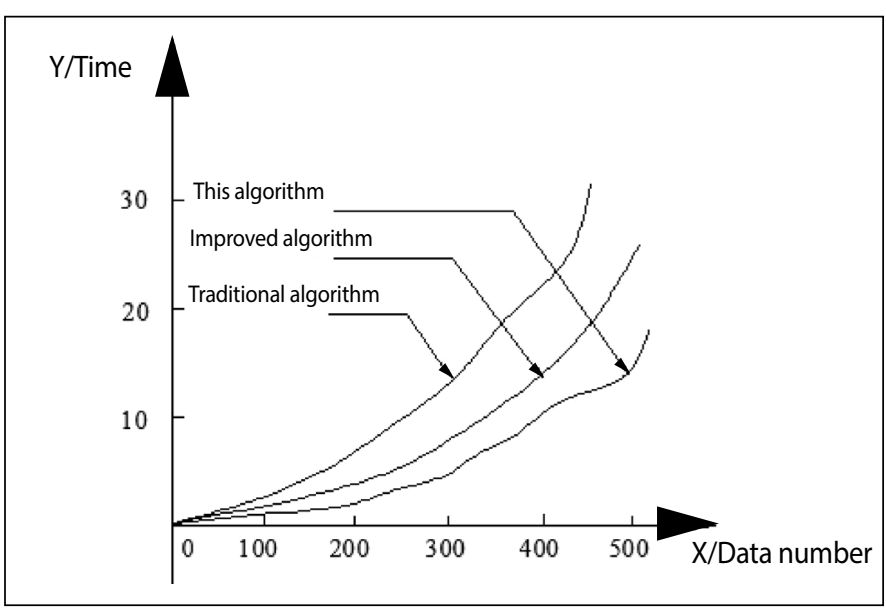

Figure 2. Comparison of genetic performance of the algorithm. 
Table 2. The algorithm convergence value table.

\begin{tabular}{c|c|c|c|c|c}
\hline & function & $\begin{array}{c}\text { Population } \\
\text { size }\end{array}$ & $\begin{array}{c}\text { Convergence } \\
\text { times }\end{array}$ & $\begin{array}{c}\text { Average } \\
\text { convergence } \\
\text { algebra }\end{array}$ & $\begin{array}{c}\text { Average } \\
\text { convergence } \\
\text { value }\end{array}$ \\
\hline $\begin{array}{c}\text { Traditional } \\
\text { genetic } \\
\text { algorithm }\end{array}$ & $f_{1}$ & 100 & 400 & 25 & 0.8999 \\
\cline { 2 - 6 } & $f_{2}$ & 200 & 382 & 31 & -196.7290 \\
\hline $\begin{array}{c}\text { Others } \\
\text { improved } \\
\text { genetic } \\
\text { algorithm }\end{array}$ & $f_{1}$ & 100 & 700 & 25 & 0.8999 \\
\cline { 2 - 6 } & $f_{2}$ & 200 & 296 & 24 & -196.7290 \\
\hline $\begin{array}{c}\text { This paper } \\
\text { improves } \\
\text { the genetic } \\
\text { algorithm }\end{array}$ & $f_{1}$ & 100 & 300 & 24 & 0.7999 \\
\cline { 2 - 6 } & $f_{2}$ & 200 & 298 & 22 & -156.7290 \\
\hline
\end{tabular}

Table 3. Real time performance calculation table of algorithm.

\begin{tabular}{c|c|c|c|c|c}
\hline Data observation & $\mathbf{5 0 0}$ & $\mathbf{1 0 0 0}$ & $\mathbf{1 5 0 0}$ & $\mathbf{2 0 0 0}$ & $\mathbf{2 5 0 0}$ \\
\hline First record time & 3 & 6 & 9 & 11 & 14 \\
\hline Second record time & 3.1 & 3.2 & 3.3 & 3.4 & 3.5 \\
\hline Third record time & 2.2 & 2.2 & 2.6 & 2.8 & 3.0 \\
\hline Time difference of real time & 7 & 7.1 & 7.2 & 7.3 & 7.4 \\
\hline
\end{tabular}

\section{CONCLUSIONS}

With the rapid development and application of computer technology, the application of computer science knowledge in basketball is also more and more extensive. The current jump movements of basketball players need reasonable analysis and reasonable guidance, because the old training methods have been unable to meet the growing demand for teaching. The video analysis and 3D detection simulation research on the throwing's accuracy of basketball players were studied in this paper. The genetic algorithm and background difference method were adopted to build the video analysis and 3D detection simulation model of the throwing's performance. According to the search method of genetic algorithm, the accuracy of the throwing action was analyzed, and the problems encountered in the actual shooting process of basketball players were studied and solved. According to the model of 3D data created by two-dimensional data, the accuracy of throwing action of basketball players has attracted the attention of experts at present. Through professional testing equipment and professional measurement personnel, the accuracy of throwing was tested. Although this algorithm may not be very perfect, it will further improve the algorithm model in the following research.

The author declare no potential conflict of interest related to this article

AUTHORS' CONTRIBUTIONS: The author has completed the writing of the article or the critical review of its knowledge content. This paper can be used as the final draft of the manuscript. Every author has made an important contribution to this manuscript. Yi Zheng: writing and execution.

\section{REFERENCES}

1. Kato S, Watanabe K, Kitamura M, Amano Y. 2A2-L08 Development of NLOS satellites detection method using 3D map and a fish-eye camera for improving GNSS positioning accuracy in urban area. The Proceedings of JSME annual Conference on Robotics and Mechatronics (Robomec). 2015;2015:_2A2-L08_1-_2A2-L08_2.

2. Mulligan D, Lohse KR, Hodges NJ. An action-incongruent secondary task modulates prediction accuracy in experienced performers: evidence for motor simulation. Psychological Research. 2015;80(4):496-509.
3. Emmonds S, O'Hara J, Till K, Jones B, Brightmore A, Cooke C. Physiological and movement demands of rugby league referees: influence on penalty accuracy. J Strength Cond Res. 2015;29(12):3367-74.

4. Zhang Y, Wang S, Phillips P, Dong Z. Detection of Alzheimer's disease and mild cognitive impairment based on structural volumetric MR images using 3D-DWT and WTA-KSVM trained by PSOTVAC. Biomedical Signal Processing \& Control. 2015,21:58-73. 